SCIREA Journal of Education

http://www.scirea.org/journal/Education

November 15, 2021

Volume 6, Issue 6, December 2021

SCIREA

\title{
Research on intelligent teaching model from the perspective of deep learning
}

\author{
Jing Huang, Yong Zhang* \\ Yancheng Teachers University, Jiangsu 224002, China \\ * E-mail of the corresponding author: zyyctc@126.com \\ The research is part of the achievements of the research project of higher education reform in \\ Jiangsu Province.No.2019JSJG257(Sponsoring information)
}

\begin{abstract}
Deep learning and shallow learning (or surface learning) are two types of learning that are classified according to the level of understanding that students achieve in learning. As the concept of education continues to be upgraded, the cultivation of higher-order thinking in students is being emphasized more and more, and deep learning is being strongly promoted as an inevitable trend of the times. In the traditional teaching mode, deep learning is difficult to be implemented. With the continuous use of modern information technology in the field of teaching and learning, intelligent teaching and learning have brought convenience to deep learning. The implementation of an intelligent teaching model to achieve deep learning needs to meet at least three major requirements: the creation of an intelligent teaching environment, the cultivation of teachers' intelligent teaching ability, and the enhancement of students' self-learning awareness. Taking Jack London's "Love of Life" as an example, this paper
\end{abstract}


explores how to develop deep learning under the intelligent teaching model.

Keywords : deep learning; intelligent teaching model; requirements; case

The development of modern information technology has brought about a profound change in education. The new intelligent teaching model built by using "Internet + " and dynamic data analysis is a great challenge to traditional teaching concepts. This requires teachers to abandon the previous indoctrination mode of teaching, highlight the concept of "student-centered," return the initiative of learning to students so that students can truly become the master of learning. In the process of active thinking, active exploration, and active discovery, students can stimulate their interest in learning and unleash their learning potential, thus achieving all-round development. This study attempts to develop students' independent learning and creative thinking skills through the intelligent teaching model and then to achieve the purpose of deep learning.

\section{I. deep learning and shallow learning (or surface learning)}

The issue of student learning is not only the original intention and mission of educators but also the fundamental purpose of educational activities. Every lesson, assignment, and test for students and every teaching and research discussion for teachers stems from and culminates in this question. For teachers, how students should learn and how effective their learning is, are the topics they must focus on. As early as 1976, in a paper titled "On qualitative differences in learning: I-Outcome and Process," co-authored by American scholars Marton and Saljo, the concepts of "deep learning" and "shallow learning" (or surface learning) were first introduced. ${ }^{[1]}$ Since then, the research related to deep learning and shallow learning has been intensified at home and abroad. For example, Entwistle analyzed the impact of learning methods on deep learning in "Approaches to Learning and Levels of Understanding."[2] In Student Learning Research: Retrospect and Prospect, Ramsden analyzed the characteristics of 
shallow learning (or surface learning) and deep learning and argued that the quality of student learning depends on learning methods and deep learning behaviors. ${ }^{[3]}$ In "Understanding deep learning," Sun Yinli compares deep learning with shallow learning (or surface learning), arguing that deep learning "is the acquisition of advanced cognitive skills, such as analyzing, interpreting, synthesizing, synthesizing, and evaluating information or applying new skills, rather than the simple stacking, copying, and describing of information. ${ }^{[4]}$ Zhang Hao, Wu Xiujuan et al. analyzed the nature of deep learning in the paper "Objectives of deep learning and evaluation system construction." They argue that "deep learning is an active, inquiry-based, and comprehension learning style that requires learners to master unstructured deep knowledge and engage in critical higher-order thinking, active knowledge construction, effective transfer application, and authentic problem solving, and thus achieve Metacognition ability, problem-solving ability, critical thinking, and creative thinking." ${ }^{[5]}$ In summary, deep learning and shallow learning (or surface learning) are two different types of learning based on the level of understanding students have achieved in their learning. Deep learning is a deepening and expansion of shallow learning (or surface learning). Students achieve self-construction of knowledge and gain higher-order cognition through active participation in the learning process and a deep understanding of what they have learned, students achieve self-construction of knowledge and thus gain higher-order cognition.

Deep learning and shallow learning (or surface learning) take very different approaches to learning. In terms of instructional goals, shallow learning (or surface learning) requires memorizing large amounts of information. On the other hand, deep learning helps students build their own understanding and learn to apply their knowledge to solve real-world problems. Shallow learning (or surface learning) relies on mechanical memorization rather than understanding. Its possession of knowledge is often transient and superficial, while deep learning enables the transfer and application of knowledge. In this paper, Bloom's taxonomy of educational objectives is used as an example. In 1956, Bloom, a professor at the University of Chicago, classified educational objectives into six cognitive levels ${ }^{[6]}$ to show the gradual development process of students' advanced thinking skills. Among them, cognition, understanding, and application belong to shallow learning (or surface learning), while analysis, 
synthesis, and evaluation belong to deep learning. The specific connotations are as follows.

\begin{tabular}{|c|c|c|}
\hline \multicolumn{2}{|c|}{ cognition level } & Definition \\
\hline \multirow{3}{*}{$\begin{array}{c}\text { shallow } \\
\text { learning (or } \\
\text { surface } \\
\text { learning) }\end{array}$} & cognition & Recall and recollection of prior knowledge \\
\hline & understanding & Ability to translate, interpret, or speculate about knowledge. \\
\hline & application & Ability to apply what you have learned. \\
\hline \multirow{3}{*}{ deep-learning } & analysis & $\begin{array}{l}\text { Breakdown of the overall knowledge and understanding of the } \\
\text { connections between the components. }\end{array}$ \\
\hline & synthesis & Ability to reorganize what you have learned into a new whole \\
\hline & evaluation & Ability to make value judgments based on criteria \\
\hline
\end{tabular}

Of these six cognition levels, the first three categories belong to the primary level of cognition, which generally has direct, clear, unambiguous answers and is simply a perceptual exercise in recalling knowledge of a subject. The latter three categories belong to the advanced level of cognition, which usually does not have a single correct answer and emphasizes the intrinsic understanding of knowledge, often with different answers from different perspectives. Biggs believed that deep learning is the proactive understanding of knowledge, high-level processing, and critical construction of a body of knowledge in order to better apply what has been learned. ${ }^{[7]}$

In the traditional teaching mode, the teacher is in the main position of teaching activities. The teacher's thinking and viewpoint have always shaped students' learning. The traditional indoctrination and transmission mode of teaching puts students in a passive learning situation. Students are under pressure to memorize and apply mechanically, lacking active critical spirit and reflective spirit, so the knowledge they acquire is often fragmented and isolated, belonging to shallow learning (or surface learning). Suppose education is to develop students' core literacy and cultivate high-quality talents. In that case, the original teaching philosophy must be changed so that teachers can become facilitators, organizers, and guides of students' learning, encouraging students to take the initiative to discover problems, solve them and form higher-order thinking based on their own needs, thus realizing deep learning. 


\section{Three requirements for implementing the intelligent teaching model in a}

\section{deep learning perspective}

With the continuous application of modern information technology in the field of teaching and learning, intelligent teaching brings convenience to deep learning. "intelligent teaching" includes both "intelligence" and "teaching". "smart" is an intelligent technology tool, and "teaching" is the process of teachers transferring knowledge and skills to students. Therefore, "intelligent teaching" is the product of the deep integration of information technology and education. Its implementation involves three levels of intelligent teaching tools, teachers and students, and is "a balance between the complex relationship between teaching technology, subject knowledge, and teaching methods". ${ }^{[8]}$ To implement intelligent teaching to achieve deep learning, in general, it needs to meet at least three requirements, namely: the creation of a intelligent teaching environment, the cultivation of teachers' intelligent teaching ability, and the enhancement of students' self-learning awareness.

\section{(i) The creation of an intelligent teaching environment}

Unlike traditional teaching, intelligent teaching must create a specific teaching environment, which means using modern scientific and technological means to build up an intelligent, personalized, and digital modern teaching environment. It includes three specific aspects.

First, the creation of an intelligent teaching environment. Mobile terminals such as smartphones, computers, or iPads are indispensable in the implementation of teaching and learning. The relevant intelligent teaching platform or intelligent teaching tool is also a necessary element for implementing intelligent teaching. Intelligent teaching can only be carried out with the support of a mobile terminal, a intelligent teaching platform, or a tool.

Second, the creation of a personalized teaching environment. For example, provide relevant open courses for students to learn independently. Prepare relevant high-quality lessons, micro-lessons, research papers, etc., and upload them to the intelligent teaching platform as a supplement to the learning content. Collect relevant audio, video, animation, pictures, etc., to make the smart classroom more vivid. 
Third, the creation of a digital teaching environment. Teachers make full use of the sign-in, questionnaire, voting, discussion, and test functions of the intelligent teaching tool and can get a series of digital statistics of the teaching process in the background management of the teaching tool so that they can understand the effect of intelligent teaching more directly and objectively.

\section{(ii) The development of teachers' intelligent teaching skills}

Deep learning is not the same as student-directed learning but rather a higher-order cognition of knowledge formed under the guidance of a teacher. The role of the teacher in this process cannot be overlooked. Intelligent teaching based on deep learning puts new demands on teachers. Zhu Zhiting ${ }^{[9]}$ mentioned that teachers should improve their information-based teaching ability. Teachers should not only be able to use information technology to explain, inspire, demonstrate, guide, connect and give feedback, but also to "use information technology to support students' communication and cooperation, inquiry and construction, independent learning and personalized development. This places new demands on teachers, who need to do at least the following four things.

First, the concept of intelligent teaching needs to be deeply grasped. The essence of intelligent teaching is a kind of teaching that pursues wisdom and creativity. Its goal is to cultivate students' intellectual ability, to put students at the center, and to give full play to their main role. Therefore, teachers should make adequate instructional designs guided by the new teaching philosophy. "If the concept of imparting knowledge with the help of modern information technology but still applying the cramming method in teaching, then it is just changing the form." $[10]$

Second, information technology teaching tools need to be mastered. Only by skillfully applying the hardware and software facilities of intelligent teaching can teachers create a certain teaching situation and enhance students' active learning awareness.

Third, a reasonable intelligent teaching program needs to be devised. Through continuous training and exploration, teachers must design a variety of intelligent teaching solutions for each part of teaching and perfectly integrate the various functions of intelligent teaching tools 
with complete teaching activities in order to highlight the centrality of students and thus realize the communication between teachers and students or between students at any time. The use of intelligent teaching tools does not lead to substantial improvements in learning efficiency and effectiveness if teachers do not engage in adequate instructional design.

Fourth, a broader knowledge of various subjects is needed. In intelligent teaching, promoting students' deep learning cannot rely solely on teachers' lectures, but the role of teachers as organizers and guides of learning cannot be ignored. Teachers should not only be able to master the subject they teach in detail but also have some knowledge of other related subjects. Only in this way can they effectively apply various teaching strategies to expand students' knowledge and develop their learning mindset, thus realizing the purpose of deep learning.

\section{(iii) Student awareness of independent learning}

Students are the implementers and finishers of deep learning. In traditional learning environments, students are often passive recipients of learning content, lacking a sense of active exploration, and their learning outcomes are often superficial. In the intelligent teaching model, to achieve deep learning, it is necessary to enhance students' awareness of self-directed learning. And the improvement of students' sense of autonomy does not happen overnight but requires various efforts, such as:

First, strict discipline is guaranteed. Teachers need to establish reward and punishment mechanisms to guarantee students' implementation of independent learning.

Second, effective interest stimulation. Teachers need to stimulate students' interest in learning through various forms such as multimedia, videos, pictures, and topic discussions, and then guide them to learn independently and think actively.

Third, a good encouragement mechanism. Teachers need to focus on encouragement and positive guidance to create a positive learning environment and enhance students' awareness of independent learning.

It is also important to note that increasing students' awareness of self-directed learning is not the same as encouraging students to engage in full deep learning. Our emphasis on deep learning does not exclude shallow learning (or surface learning). Some people think that deep 
learning is good and shallow learning (or surface learning) is bad. This view is inherently superficial because knowledge itself cannot be judged by good or bad. Shallow learning (or surface learning) is based on memorization, but some factual basics, mathematical formulas, etc., can only be memorized by memory. Moreover, sometimes deep learning is based on shallow learning (or surface learning). Only after mastering the pronunciation and interpretation of the words in the text can we talk about a deeper understanding of the idea of the text and gaining the ability to learn by analogy, draw inferences about other cases from one instance. Therefore, in the process of raising students' awareness of self-directed learning, attention should be paid not only to raising awareness of deep learning but also not to ignoring shallow learning (or surface learning).

\section{The case of intelligent teaching in the perspective of deep learning}

Intelligent teaching from the perspective of deep learning aims to break through the time and space limitations of traditional classrooms and realize learning anytime and anywhere before, during, and after class. Break through the limitations of teacher-student interaction and realize barrier-free communication between teachers and students, and between students and students. Break through the limitation of traditional paper test correction and feedback process, and realize the efficient operation of "instant examination and feedback". Break through the limitation of traditional teaching in which teachers teach according to uniform standards, and realizes personalized guidance; break through the teacher-centered mode of traditional teaching, and realize student-centered and problem-oriented teaching. The general model of teaching is as follows.

\begin{tabular}{|l|l|l|}
\hline \multicolumn{1}{|c|}{ Before class } & \multicolumn{1}{c|}{ In the class } & \multicolumn{1}{c|}{ After class } \\
\hline $\begin{array}{l}\text { 1.Upload the preview list } \\
\text { 2.Uploading teaching resources }\end{array}$ & 1.Ask questions & 2.To solve the problem \\
3.Online interactive & 3.The interactive discussion & 1.Big data evaluation \\
4.Online questionnaire & 4.Explain key points & 3.Upload quality resources \\
5.The online test & 5.The online test & 5.Extension work \\
\hline
\end{tabular}

The following is an example of "Love of Life" by Jack London, an American author, to explore how to develop deep learning under the intelligent teaching model. 


\section{(i) In-depth preview before class}

In traditional teaching, class preparation usually consists of teacher preparation and student preview, so there is a lack of connection between teachers and students. Students' preview is also often superficial, such as preview in language subjects, where students focus on mastering word explanations, word pronunciation, superficial content of the text, and basic overview of the writer. What students get from their pre-course preview is mostly some basic and factual information, which cannot achieve the purpose of deep learning.

The implementation of an intelligent teaching model can effectively improve this problem. Before the class, teachers can post a preview list through an intelligent teaching platform to guide students to think independently. For example, in "Love of Life" it describes the tenacity of the main character "he" in the face of extreme circumstances. But if students only marvel at "his" love for life after studying this text, such learning is superficial, and students' gains are limited. Before the class, teachers can use the intelligent teaching platform to upload movies and videos about the theme of "extreme survival", and ask students to watch the movies and exchange them in the discussion forum of the intelligent teaching platform. In this way, students' minds are immediately active, and language learning becomes lively and interesting. The theme of "Love of Life" is naturally presented to the students during their discussions. On this basis, students can be asked to read this novel by Jack London and complete questionnaires and test assignments on the intelligent teaching platform on related basic knowledge. In this way, students will naturally compare film and fiction in their reading and assignments and then develop a sense of reflection and creative ability.

\section{(ii) Deep involvement in the class}

In the traditional classroom, students only follow the teacher's thinking activities and passively receive knowledge. This kind of "teaching"-centered instruction not only fails to stimulate students' participation but also fails to achieve the purpose of deep learning. In the intelligent teaching model, teachers can break the limitations of the traditional classroom through a variety of formats.

Teachers can use task-based teaching, question-based teaching, and reflective teaching 
methods to start teaching. Teachers can use intelligent teaching tools to ask questions and guide students to think about what the purpose of the question is, what aspects of the question can be studied, how the results of the study can be of practical value to them, and so on. For example, when students study Love of Life, teachers can ask students what life is, how powerful it is, what life and death tests the main character faces in the wilderness, why the main character survives beyond his limits, what new understanding of the life you have gained from it, and so on. Students can engage in group discussions and collaborative learning. All students participate in the discussion forum of the intelligent teaching platform, which breaks the limitation that only a few students can answer questions passively in traditional classrooms, and thus allows all students to actively think and speak up. The teacher will ask questions while guiding students to ask new questions and to think about why they are asking such questions in this place, etc. In the process of constantly asking questions and solving problems, students will develop positive learning attitudes and in-depth study habits. At the end of a period of learning tasks, teachers can give special explanations to students on the important and difficult points of teaching and use the testing function of an intelligent teaching platform to issue accompanying test questions. Through the test results, teachers can have a comprehensive grasp of students' learning so that they can carry out personalized instruction.

\section{(iii) In-depth extension after the class}

In traditional classroom teaching, students' after-school homework is mainly review and consolidation, which not only has a long process and slow feedback but also has little effect on in-depth expansion. In-depth extension after the class can be achieved through intelligent teaching by extending classroom learning in two ways.

On the one hand, teachers' big data assessment and personalized guidance. Teachers can use the big data statistics function of an intelligent teaching platform to comprehensively grasp students' learning dynamics so as to make an objective assessment of teaching operation and teaching effect. Teachers can individualize instruction to suit each student. For the existence of common problems, teachers can release quality teaching resources or make up teaching videos for all students to re-sort so as to improve the depth of students' learning. 
On the other hand, students' in-depth reading and practical experience. Teachers can ask students to read or revisit classic survival stories, such as Zweig's "The Fight for the South Pole" and Defoe's "The adventures of Robinson Crusoe," and talk about their feelings and reflect on the value of life by submitting short essays and participating in discussions. Teachers actively participate in the process of sensing life, forming a good interaction between teachers and students, thus combining theory and practice to achieve deepening and sublimation of learning.

\section{Conclusion}

With the development of modern information technology, it can effectively solve many problems that are difficult to solve in the traditional teaching mode. The implementation of the intelligent teaching model enables students to achieve deep learning through independent learning, allowing teachers to differentiate teaching according to students' individual characteristics and thus improve teaching quality. With the further development of the information age, the changes of intelligent teaching in education will continue further. Under the intelligent teaching model, there will be more and more attention on how to realize deep learning. This paper analyzes three requirements for the successful implementation of the intelligent teaching model from the perspective of deep learning and shows how to implement deep learning in the intelligent teaching model through case studies. In the intelligent teaching model, how to assess the achievement of deep learning will be the next question to be studied.

\section{References}

[1] Marton F, Saljo R. On qualitative differences in learning: I-Outcome and Process[J]. British Journal of Educational Psychology, 1976,46(1):4-11.

[2] Entwistle, N.J, Hanley, Maureen, Ratcliffe, G. Approaches to Learning and Levels of Understanding[J]. British Educational Research Journal, 5(1):99-114.

[3] Ramsden, Paul. Student Learning Research: Retrospect and Prospect[J]. Higher 
Education Research \& Development, 4(1):51-69.

[4] Sun Yinli. Awareness of deep learning $[\mathrm{J}]$. Journal of Shaoxing University,2007,27(11):34-36.

[5] Zhang Hao, Wu Xiujuan, Wang Jing. Objectives of deep learning and evaluation system construction[J].China Educational Technology (Theory of Educational Technology), 2014(7):51-55.

[6] B.S. Bloom, D.R. Krathwohl, B.B. Masia. Bloom's taxonomy of educational objectives: Pearson Education[M], 1984.

[7] Biggs J. B. Individual differences in the study process and the quality of learning outcomes[J]. Higher Education, 1979(8): 381-394.

[8] Lu Wancheng. Smart Education - The new frontier of education informatization[J]. Education Forum. 2016(03):7.

[9] Zhu Zhiting. New development of smart education: from flipped classroom to smart classroom and smart learning space[J]. Open Education Research.2016,22(01):18-26+49.

[10] Wang Dong, Zhang Min, and Wang Xin. Smart Classroom Practices in University Physics[J]. Kejifeng, 2021(26): 78-80. 